\title{
Assessing the energy performance of modern glass facade systems
}

\author{
Abdelsalam Aldawoud * \\ Architectural Engineering Department, University of Sharjah \\ Sharjah, United Arab Emirates
}

\begin{abstract}
The design and construction of the building envelope have a significant effect on the energy performance of buildings because the building envelope physically separates the exterior from the interior environment. The use of glass as a component of the building envelope has been significantly growing since its initial introduction as a building material. The glass is necessary for aesthetics, ventilation, and daylight. Despite the many benefits to the building, the glazing still provides the lowest insulating value. Of all envelope components, windows and skylights represent major sources of thermal losses and gains which impact the thermal comfort in buildings. Therefore, window size, type, and design are the most important consideration for reducing the need for space heating and cooling. This study investigates the thermal performance and the effectiveness of various modern glass facade systems to improve building efficiency levels. The main objectives of this study are to provide a comparison and evaluation of glazing systems and to establish guidelines for energy-efficient envelope design that provide architects and designers with a basic framework for the selection of the most appropriate glazing systems. It has been noted that the spectrally selective system and the electrochromic glazing system show high energy efficiency compared to other tested glazing systems.
\end{abstract}

\section{Introduction}

The building construction sector in the UAE has witnessed a fast track growth in last three decades. According to the 2015 Buildings Energy Data Book, energy usage in the UAE has grown at an annual average of 4 percent over the past six years, with projections that it will increase to 5 percent through 2020 [4]. Overall electricity consumption has more than doubled in the last 10 years, at a pace that will be difficult to provide for over the long term.

The building sector in UAE is by far the largest energy consumer and a major contributor to Greenhouse gasses (GHG) emissions. To reduce the growth of energy consumption, a comprehensive energy efficiency measures should be adopted to improve building efficiency. The design of a building façade is considered a key design element that

\footnotetext{
* Corresponding author: aaldawoud@sharjah.ac.ae
} 
could significantly influence the building energy performance and its environmental impact. In UAE, most of the new buildings adopt the concept of a fully glazed façade because of the advancement of façade construction technology and physical properties of glass. However, the interest among architects and engineers to design light and transparent buildings with fully glazed envelopes to access more daylight [2]. This trend could lead to unintended consequences of increasing the energy consumption of the construction due to higher solar heat gain.

Despite the fact that fenestration systems are used as a method to provide a visual connection to the outside environment, they are the weakest energy link of the building envelope [1]. Careful choice of glazing type could improve the building envelopes energy performance and reduce the consumption by decreasing the lighting and heating and cooling loads in buildings. This could provide the desired natural daylight and the visual connection to the outside in well-designed buildings [3].

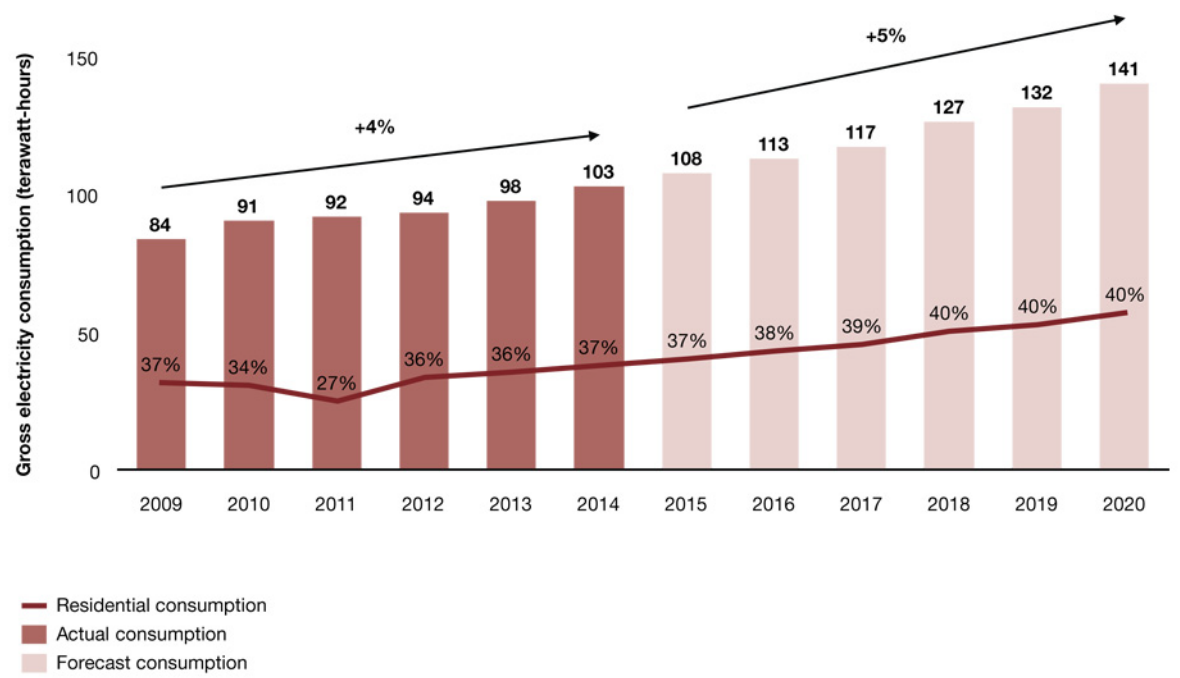

Fig. 1. UEA electricity consumption and the forecast in the next five years.

Source: Economist Intelligence Unit (EIU), 2015; International Energy Agency (IEA), 2015.

Despite the fact that fenestration systems are used as a method to provide a visual connection to the outside environment, they are the weakest energy link of the building envelope [1]. Careful choice of glazing type could improve the building envelopes energy performance and reduce the consumption by decreasing the lighting and heating and cooling loads in buildings. This could provide the desired natural daylight and the visual connection to the outside in well-designed buildings [5].

This study investigates the thermal performance and the effectiveness of various modern glass facade systems to improve building energy efficiency levels. The main objective of this study is to provide a comparison and evaluation of glazing systems. The intention is to establish some strategies and guidelines for energy-efficient envelope design that provide architects and designers with a basic framework for the selection of the most appropriate glazing systems. This study also aims to improve the energy performance of buildings in UAE by examining and evaluating different glazing systems which could have a direct impact on solar radiation and heat gain performance. 


\section{Methodology}

For the purpose to investigate the thermal energy and the effectiveness of various glazing systems, a model which represents an office building is created in DesignBuilder simulation program which is the only software used in the analysis. DesignBuilder is an energy modeling software developed using EnergyPlus (U.S. DOE, 2011) as the analysis engine. An energy performance calculation for a whole building is made to compare the performance of the Façade system to other types of façades used. In all simulation scenarios, assumptions and simplifications are made; however, these assumptions and simplifications are maintained for each scenario, so that the glazing type was the only variable that changed.

\subsection{Geometry}

The reference building model is eight stories with a total floor area of $16335 \mathrm{~m} 2$. The model has the same geometrical proportion, length, width, and height. The construction template used for the building was the same for all glazing alternatives. The glazing type was the only variable that changed throughout the simulation process. Figure 2 shows the model created in DesignBuilder. Since the only variable is the glazing type and the high level of detail will not affect the final results, the template for "Medium Weight, is used for the construction of the walls and moderate Insulation" is used for the walls, floors, ceilings and roofs.

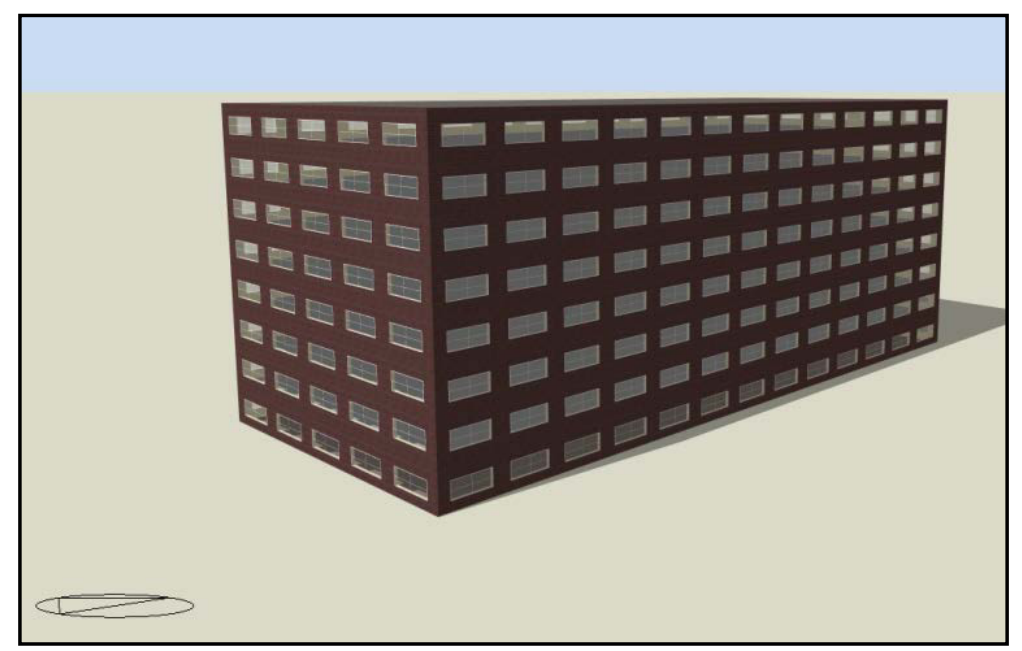

Fig. 2. Building model created using Design Builder.

\subsection{Classification of the climate in Sharjah}

The energy performance analyses are conducted by assuming buildings located in Sharjah, $25^{\circ} 33^{\prime} \mathrm{N} 55^{\circ} 52^{\prime} \mathrm{E}$. The climate in Sharjah as in UAE is a hot sunny and characterized by high levels of temperature, humidity, and sunshine. The summer months, from June to September, are too hot for comfort. The temperatures range from $10^{\circ} \mathrm{C}$ in winter to a high $48^{\circ} \mathrm{C}$ at the height of summer. The weather file used in the simulation is obtained by measurements at the Sharjah International Airport station. 


\subsection{Type of glazing investigated}

A wide range of glazing technologies is selected in the study. The average window-wall ratio of the whole building is about $30 \%$. The reference model scenario has the same opening area, and this is kept for all generated alternatives throughout the simulation process. The window wall ratio and the openings distribution on different façade's orientation are demonstrated in Figure 2. Table 1 demonstrates the numeric distribution which shows that north and south facing windows area is about $60 \%$ of total windows area of the building.

Table 1. Window-wall ratio.

\begin{tabular}{|l|c|c|c|c|c|}
\hline & Total & North & East & South & West \\
\hline Gross Wall Area [m²] & 5600 & 1960 & 840 & 1960 & 840 \\
\hline Window Opening Area [m²] & 1618.86 & 568.51 & 240.91 & 568.51 & 240.91 \\
\hline Gross Window-Wall Ratio [\%] & 28.91 & 29.01 & 28.68 & 29.01 & 28.68 \\
\hline
\end{tabular}

The glazing systems can be divided into several categories. Several glazing technologies are selected and described below. The thermal and optical properties are summarized in Table 2.

- Basic Standard Single Clear Glass: These products are comprised a single pane of standard glass.

- Insulating Glass Units: These products use two panes of glass separated by an air space to control heat transfer. A common configuration is two $1 / 4$ " panes separated by a $1 / 2$ "airspace. The primary principle behind this technology is that conduction is reduced due to the airspace.

- Glazing filled with Inert Gas: Gas other than air such as Argon or Krypton is used to suppress conduction and convection behavior between the two panes.

- Electrochromic Glazing: These products operate similarly to Liquid Crystal Devices. However, they allow for the user to vary the amount of current through the device to vary the degree of tint in the window.

- Coatings: These products that are applied directly to the glazing control solar heat gain by limiting those wavelengths of light that are allowed to pass through and those that are reflected. These products are commonly referred to as Low-E coatings.

- Reflective Glazing Systems: reflective glass has a mirror-like appearance and reflects and absorbs a major proportion of the sun's direct short wave solar radiation. The degree of reflectivity is dependent on the type of coating and the orientation of the glass.

- Spectrally Selective Systems: These products typically involve films, tints, or coatings; which reflect selected wavelengths of light, while allowing others to pass through. There is a broad range of performance qualities that can be achieved using these products. 
Table 2. Thermal and optical properties for investigated glazing systems.

\begin{tabular}{|l|c|c|c|c|}
\hline Variables & SHGC & $\begin{array}{c}\text { Direct Solar } \\
\text { transmission }\end{array}$ & $\begin{array}{c}\text { Light } \\
\text { transmission }\end{array}$ & $\begin{array}{c}\text { U-value } \\
\text { (W/m²-K) }\end{array}$ \\
\hline Single Clear glass 6mm & 0.819 & 0.775 & 0.881 & 5.778 \\
\hline Double Clear 3mm-6mm Air & 0.762 & 0.8 & 0.812 & 3.159 \\
\hline Triple clear 3mm-6mm Air & 0.684 & 0.595 & 0.738 & 1.757 \\
\hline $\begin{array}{l}\text { Double metallic reflective coating Clear } \\
\text { 6mm-13mm Arg }\end{array}$ & 0.179 & 0.8824 & 0.127 & 2.109 \\
\hline $\begin{array}{l}\text { Double Electrochromic absorptive colored } \\
\text { 6mm-6mm Air }\end{array}$ & 0.197 & 0.08718 & 0.114 & 2.429 \\
\hline $\begin{array}{l}\text { Double Low-emissivity LoE (e2=.1) Clear } \\
\text { 3mm-13mm Air }\end{array}$ & 0.598 & 0.538 & 0.769 & 1.786 \\
\hline Triple low-e filled with argon & 0.474 & 0.351 & 0.661 & 0.786 \\
\hline $\begin{array}{l}\text { Double Electrochromic reflective colored } \\
\text { 6mm-6mm Air }\end{array}$ & 0.182 & 0.078 & 0.137 & 2.429 \\
\hline $\begin{array}{l}\text { Double Low-e Spectrally selective Clear } \\
\text { 3mm-13mm-6mm Air }\end{array}$ & 0.43 & 0.359 & 0.691 & 1.646 \\
\hline Triple Clear 3mm-13mm Air & 0.474 & 0.358 & 0.661 & 0.982 \\
\hline $\begin{array}{l}\text { Double Reflective-low-transmittance Tint } \\
\text { 6mm-6mm Air }\end{array}$ & 0.168 & 0.056 & 0.073 & 2.788 \\
\hline
\end{tabular}

\section{Results and discussion}

The results of different glazing systems alternatives energy performance have been collected and compared with benchmark condition. The results showed that the energy performance varies with the glazing type. In general, results show that the "Double Low-E Spectrally selective Clear $3 \mathrm{~mm}-13 \mathrm{~mm}-6 \mathrm{~mm}$ Air" and the "Double Electrochromic absorptive colored $6 \mathrm{~mm}-6 \mathrm{~mm}$ Air" Energy performances are the best among all investigated glazing systems (Figure 3). These two systems have the potential to save up to almost $60 \%$ compared to the single glazing energy performance.

Accordingly, single clear glass energy performance is the worst among all investigated glazing systems and therefore served as the baseline by which the improvements of the other systems were measured. Heat losses through the glass unit are reduced by optimizing the glazing gap between the two glass panes when filled with air. The glazing with the gap width of $13 \mathrm{~mm}$, performs better than glazing with the gap width of $3 \mathrm{~mm}$ or $6 \mathrm{~mm}$. While double clear glazing reduction is about $24 \%$ less than single glazing energy performance, Double; reflective and Low-E glazing reduces the energy transmission by $37 \%$ compared to the single glazing energy performance. 


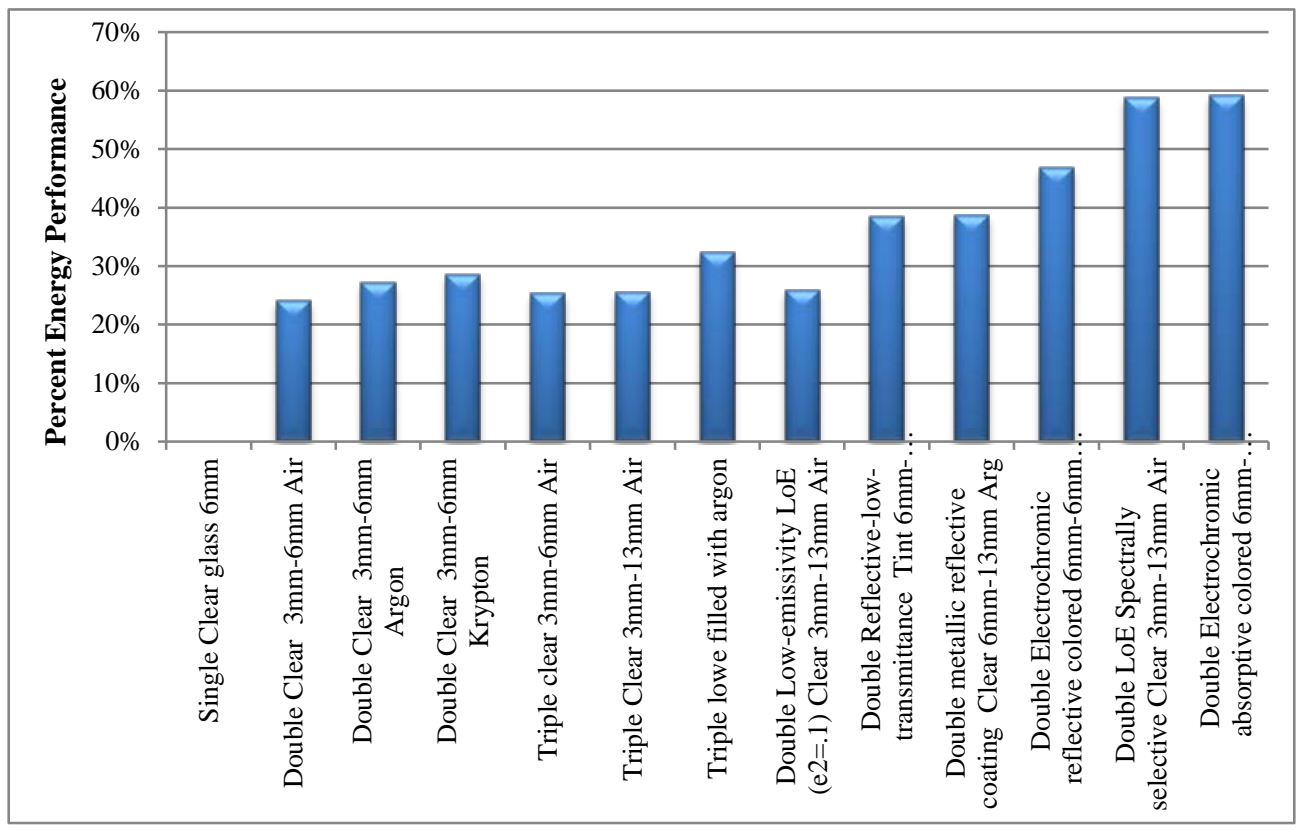

Fig. 3. Energy performance of different glazing systems alternatives.

The results also show that the type of gas fills significantly improve the energy efficiency of the glazing system. Compared with glazing that has a gap filled with air (density: $1.29 \mathrm{~kg} / \mathrm{m} 3$ at $0^{\circ} \mathrm{C}$ ), nearly $15 \%$ performance increase is achieved by adding argon gas (density: $1.78 \mathrm{~kg} / \mathrm{m} 3)$ to glazing unit. Adding krypton gas $(3.71 \mathrm{~kg} / \mathrm{m} 3)$ to the glazing gap improves the performance of the glazing system by almost $5 \%$ over the argon filled glazing gap and about $20 \%$ over air filled glazing gap. The energy performance of different glazing systems with different gas fills is demonstrated in Figure 4.

In addition, it has been found that using clear triple glazing enhances the energy performance by almost $26 \%$ compared to single glazing base case. On the other hand, triple glazing with Low-E filled with argon gas has even better performance with a potential of a reduction of almost $33 \%$.

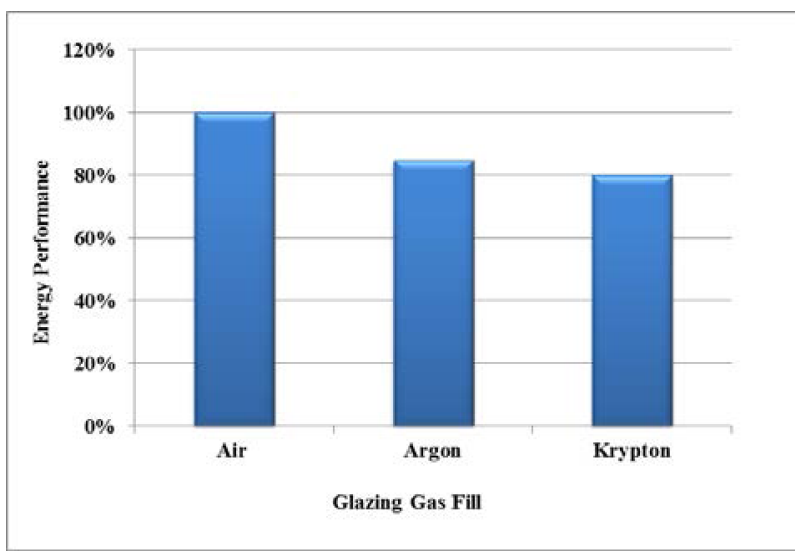

Fig. 4. Energy performance of different glazing systems with different gas fill. 


\section{Conclusions}

This analysis involved the comparison of the impact of different glazing systems on the annual energy consumption of buildings. This is mainly related in hot humid climate to solar heat gain which impacts the cooling load and the total energy consumption of buildings. Results show that the performances of the investigated glazing systems vary and the best glazing performers are those with the greatest insulating properties. Significant reductions in energy consumption due to the heat gain of solar transmission could be reached by using spectral selective systems that focus on reducing heat gains and blocking direct sun, while permitting daylight and views to the outdoors. Based on the results of this analysis, the following concluding remarks can be made:

- The amount of energy of heating and cooling consumed in buildings depends on greatly on the glazing type which impacts solar heat transmission. Based on energy performance, single glazing is a very poor. Double and triple glazing has better energy performance.

- In hot humid climate, the glazing solar heat gain coefficient (SHGC) and the Uvalue of have a significant impact on the energy performance of each glazing type. Low solar heat gain coefficient and low U-value glazing are important factors to consider when selecting the appropriate glazing type. They are greatly effective in reducing the amount of heat entering the building.

- Smart glazing technologies including electrochromic and spectral selective systems can control the direct solar gain and help reduce the heat gain due to solar radiation.

- The size of the gap between glazing panes, and the type of the gas fill impact the performance of glazing. Argon or Krypton gas fills show better performance than air.

- $\quad$ Tint layers and Low-e coatings improve the performance of the glazing. Tinted and Low-E double glazed exhibits better performance in blocks some of the solar radiation.

\section{References}

1. Aldawoud, A. (2012). Conventional fixed shading devices in comparison to an electrochromic glazing system in hot, dry climate. Energy and Buildings 59 (2013), pp. 104-110.

2. Arasteh, D., Goudey, H., Huang, J., Kohler, C. \& Mitchell, R. (2006). Performance Criteria for Residential Zero Energy Windows. Lawrence Berkeley National Laboratory, Berkeley CA 94720.

3. Chi-Ming, L. \& Yao-Hong, W. (2011). Energy-Saving Potential of Building Envelope Designs in Residential Houses in Taiwan. Energies 4, (2011), pp. 2061-2076.

4. International Energy Agency (IEA), 2015. World Energy Outlook 2015 - United Arab Emirates Energy Efficiency.

5. Ochoa, C.E., Aries, M.B.C., Loenen, E.J.V. \& Hensen, J.L.M. (2012). Considerations on design optimization criteria for windows providing low energy consumption and high visual comfort. Applied Energy 95 (2012), pp. 238-245. 